\title{
Physical Properties of Films Based on Gelatin and Dialdehyde Starch with Different Oxidation Degrees
}

\section{LE THI BICH NGUYET ${ }^{1}$ and VINH TIEN NGUYEN ${ }^{2 *}$}

${ }^{1}$ Science Research and Technology Transfer Institute, Industrial University of Ho Chi Minh City, Vietnam. 2Faculty of Chemical and Food Technology, Ho Chi Minh City University of Technology and Education, Vietnam.

${ }^{*}$ Corresponding author E-mail: tiennv@ hcmute.edu.vn

http://dx.doi.org/10.13005/ojc/370113

(Received: January 01, 2021; Accepted: February 04, 2021)

\begin{abstract}
S
In this study, dialdehyde starch (DAS) was prepared by oxidizing corn starch using potassium periodate as the oxidant. The aldehyde contents in DAS were determined using titration with hydroxylamine and were found proportional to the molar ratio of $\mathrm{KIO}_{4}: \mathrm{C}_{6} \mathrm{H}_{10} \mathrm{O}_{5}$. Fourier transform infrared spectroscopy was used to confirm the breakage of the bond between $\mathrm{C}_{2}$ and $\mathrm{C}_{3}$ in anhydroglucose units and the formation of - $\mathrm{CHO}$ group in DAS. X-ray diffractometry showed a decrease in crystallinity of starch after periodate oxidation. Thermogravimetric analysis showed reduced thermal stability of DAS in comparison with the native starch. The prepared DAS was blended with gelatin to form films by casting method. Increasing aldehyde contents in DAS from 0 to $12.2 \%$ resulted in decreased moisture contents, solubility in water, and the swelling capacity of gelatin-DAS films. The value of tensile strength and elongation at break of the gelatin-DAS films rose when the aldehyde content was low (0-3.5\%), but declined when the aldehyde content was high (3.5-12.2\%). Slight periodate oxidation is, therefore, an effective way to enhance the mechanical characteristics of blend films from DAS and other biopolymers.
\end{abstract}

Keywords: Dialdehyde starch, $\mathrm{KIO}_{4}$, Gelatin, Films, Mechanical properties.

\section{INTRODUCTION}

Nowadays, the use of petrochemical-based plastics causes nagative impacts on ecosystem because it take many years for them to decompose. To solve this problem, the development and applications of biodegradable polymeric materials, especially those from renewable resources, are needed. Among natural resources, starch is the most commonly used polymers because it is inexpensive, non-toxic, renewable, and biodegradable ${ }^{2}$. However, practical applications of starch as a plastic material were limited due to its disadvantages, such as poor mechanical properties and hydrophilic character ${ }^{3}$.

Dialdehyde starch (DAS) is an industrial starch derivative, in which the $\mathrm{C}_{2}-\mathrm{C}_{3}$ bonds of the anhydroglucose units are cleaved and the $\mathrm{CH}-\mathrm{OH}$ groups at these atoms are converted to $\mathrm{CH}=\mathrm{O}$ aldehyde groups ${ }^{4}$. When blended with other biopolymers to form films, aldehyde groups in DAS can crosslink with other functional groups (-OH and

This is an Open Access article licensed under a Creative Commons license: Attribution 4.0 International (CC- BY). Published by Oriental Scientific Publishing Company @ 2018

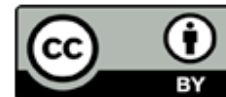


$-\mathrm{NH}_{2}$ ) and hence enhance the physicomechanical properties of the blend films. Moreno et al., reported that the improvement of hydrophobic and mechanical characteristics of the gelatin-DAS films is related to the formation of crosslinking processes in polymeric matrices while increasing the hydrophobicity of the film ${ }^{5}$.

DAS is commonly prepared by periodate oxidizing starch with $\mathrm{NaIO}_{4}$ as the most widely used reagent ${ }^{4}$. Despite lower price compared to $\mathrm{NaIO}_{4}$, $\mathrm{KIO}_{4}$ is rarely used as the oxidizing agent to prepare DAS, possibly due to its low solubility. In this study, we used $\mathrm{KIO}_{4}$ to prepare DAS from corn starch and evaluated the influence of the oxidation degrees of starch on physico-mechanical properties of gelatinDAS blend films.

\section{MATERIALS AND METHODS}

\section{Materials}

Corn starch was supplied by Rapunzel LTD. (Austria) and granular gelatin by Himedia (India). Other reagents $(36.5 \% \mathrm{HCl}, \mathrm{NaOH}(99 \%)$, $\mathrm{KIO}_{4}(99.5 \%), \mathrm{NaBr}(98 \%), \mathrm{NH}_{2} \mathrm{OH} . \mathrm{HCl}(99.5 \%)$ and glycerol (99.9\%)) were purchased from Xilong Scientific (China).

\section{Preparation of dialdehyde starch (DAS)}

The corn starch of $3.0 \mathrm{~g}$ and various quantities of $\mathrm{KIO}_{4}$ were suspended in distilled water to obtain various molar ratios of $\mathrm{KIO}_{4}: \mathrm{C}_{6} \mathrm{H}_{10} \mathrm{O}_{5}=$ $0.1,0.2$, and 0.3 (Table 1). The $\mathrm{pH}$ of solution was adjusted to 3 by adding $0.1 \mathrm{M} \mathrm{HCl}$. Then the mixtures were vigorously stirred at $35^{\circ} \mathrm{C}$ for 4 horus. After that, they were filtered and rinsed ten times $(10 \times 10 \mathrm{~mL})$ with distilled water. The products were dehydrated in a convection oven at $508^{\circ} \mathrm{C}$ for $48 \mathrm{~h}$ to obtain DAS with different aldehyde contents.

Table 1: Amounts of $\mathrm{KIO}_{4}$ used for DAS preparation with different ratios of $\mathrm{KIO}_{4}: \mathrm{C}_{6} \mathrm{H}_{10} \mathrm{O}_{5}$

\begin{tabular}{lccc}
\hline Molar ratio $\mathrm{KIO}_{4}: \mathrm{C}_{6} \mathrm{H}_{10} \mathrm{O}_{5}$ & 0.1 & 0.2 & 0.3 \\
\hline Mass of $\mathrm{KIO}_{4}(\mathrm{~g})$ & 0.425 & 0.850 & 1.275 \\
\hline
\end{tabular}

\section{Determination of aldehyde content}

A $0.25 \mathrm{M}$ hydroxylamine solution was prepared from $\mathrm{NH}_{2} \mathrm{OH}$. $\mathrm{HCl}$. The $\mathrm{pH}$ value of solution was adjusted to 5 by using sodium hydroxide $0.1 \mathrm{M}$. Dried DAS of $0.2 \mathrm{~g}$ was then added to $25 \mathrm{~mL}$ of the prepared hydroxylamine solution and magnetically stirred at $50^{\circ} \mathrm{C}$. During the reaction, the $\mathrm{pH}$ gradually decreased due to the release of $\mathrm{HCl}$ from $\mathrm{NH}_{2} \mathrm{OH} . \mathrm{HCl}$. Therefore, the $0.1 \mathrm{M} \mathrm{NaOH}$ was continuously added from a buret to remain $\mathrm{pH}=5$. After $2 \mathrm{~h}, \mathrm{pH}$ of the reaction mixture stopped decreasing, indicating the end of the reaction. The total volume of $0.1 \mathrm{M} \mathrm{NaOH}$ used VDAS was recorded. A blank determination was also conducted for $0.2 \mathrm{~g}$ of the native corn starch instead of DAS and the volume of $0.1 \mathrm{NaOH}$ used was also recorded (Vblank). The content of aldehyde in DAS was evaluated using Eq (1) ${ }^{1}$.

$$
C H O(\%)=29 \times \frac{0.1 \times\left(V_{D A S}-V_{\text {blank })}\right.}{0.2 \times 1000} \times 100
$$

\section{DAS characterization}

FTIR spectra of DAS were measured with using PerkinElmer MIR/NIR Frontier. The resolution was at $2 \mathrm{~cm}^{-1}$. The scanning region was $400-4000 \mathrm{~cm}^{-1}$.

X-ray diffraction (XRD) patterns of DAS were measured by diffractometer (Brucker D2) at ambient temperature. The scanning region was 10$90^{\circ}$ of 20 . The equipment was operated with CuKa wavelength of 1.54056 angstroms.

Thermal decomposition of DAS was investigated by thermogravimetric analyser TA200 (TA Instruments). The mass of the sample was continuously recorded while being heated in temperature range of $30-350^{\circ} \mathrm{C}$. The heating rate was $10^{\circ} \mathrm{C} /$ minute. These experiments were carried out under a nitrogen flow $(100 \mathrm{~mL} / \mathrm{min})$ to help protect the samples from oxidative degradation.

\section{Preparation of gelatin-DAS films}

Gelatin $(\mathrm{Ge})$ of $1.5 \mathrm{~g}$ was first completely dissolved in $5 \mathrm{~mL}$ distilled water by stirring at $80^{\circ} \mathrm{C}$. Then $3 \mathrm{~g}$ of DAS, $2 \mathrm{~mL}$ of glycerol and the prepared gelatin solution were added to $25 \mathrm{~mL}$ of distilled water. The blended Ge-DAS with glycerol were mixed using magnetic stirrer at $100{ }^{\circ} \mathrm{C}$ during 30 minute. After that the mixtures were left to cool down during $10 \mathrm{~min}$ and then tranfered into Petri dishes ( $15 \mathrm{~g} / \mathrm{dish}$ ). The Petri dishes with the mixtures were dehydrated at room temperature for 72 hours. The obtained films were peeled off and placed in a desiccator with a saturated $\mathrm{NaBr}$ solution to equilibriate the moisture in the films. A film with the same composition but using native corn starch (NS) instead of DAS was used as the control. 


\section{Characterization of Ge-DAS films Mechanical testing}

The tensile tester (Testometric, UK) was used to investigated the mechanical characteristics of Ge-NS and Ge-DAS films. The instrument was operated with a crosshead speed of $0.8 \mathrm{~mm} / \mathrm{s}$ (ASTM Standard method D882-12).

\section{Moisture content, solubility and swelling capacity in water}

Film samples of $2 \times 2-\mathrm{cm}^{2}$ were weighed $\left(m_{\circ}\right)$ and then dehydrated in an oven at temperature of $55^{\circ} \mathrm{C}$ for 24 hours. The weight of the prepared film samples were tested $\left(m_{1}\right)$. Then these samples were immersed in distilled water during $2 \mathrm{~h}$ at ambient temperature. After that, the films samples were removed and the surface water was cleaned using a filter paper. After weighing, the films $\left(m_{2}\right)$ were kept dry at temperature of $55^{\circ} \mathrm{C}$ during 24 horus. Then these films samples were weighed $\left(m_{3}\right)$.

The moisture content (MC) of the Ge-NS and Ge-DAS films was determined using Eq (2):

$\operatorname{MC}(\%)=\frac{m_{o}-m_{1}}{m_{0}} \times 100$

The solubility (S) of the Ge-NS and Ge-DAS films was determined using Eq (3):

$$
S(\%)=\frac{m_{1}-m_{3}}{m_{1}} \times 100
$$

Swelling capacity (SW) of the Ge-NS and Ge-DAS films was determined using Eq 4:

$S W(\%)=\frac{m_{2}-m_{3}}{m_{3}} \times 100$

\section{RESULTS AND DISCUSSION}

\section{Aldehyde content in DAS}

Table 2 shows that the aldehyde content of DAS was proportional to the molar ratio of $\mathrm{KIO}_{4}$ :anhydroglucose $\mathrm{C}_{6} \mathrm{H}_{10} \mathrm{O}_{5}$ units in corn starch. The aldehyde content of DAS increased as the molar ratio of $\mathrm{KIO}_{4} /$ glucose increased. In comparison with the study of Yu et al., with using $\mathrm{NaIO}_{4}$ as the oxidant, it was shown that the oxidation degree of starch in our study was lower, which might be due to the lower solubility of $\mathrm{KIO}_{4}$ comparing with $\mathrm{NaIO}_{4}{ }^{6}$.
Table 2: The content of aldehyde in DAS produced with different molar ratios of $\mathrm{KIO}_{4} / \mathrm{C}_{6} \mathrm{H}_{10} \mathrm{O}_{5}$

\begin{tabular}{lccc}
\hline & DAS3.5 & DAS7.4 & DAS12.2 \\
\hline $\mathrm{KIO}_{4}: \mathrm{C}_{6} \mathrm{H}_{10} \mathrm{O}_{5}$ (molar ratio) & 0.1 & 0.2 & 0.3 \\
Aldehyde content (\%) & 3.5 & 7.4 & 12.2 \\
\hline
\end{tabular}

FTIR

FTIR was applied to investigate the changes in structure when native starch was oxidized to DAS (Figure 1).

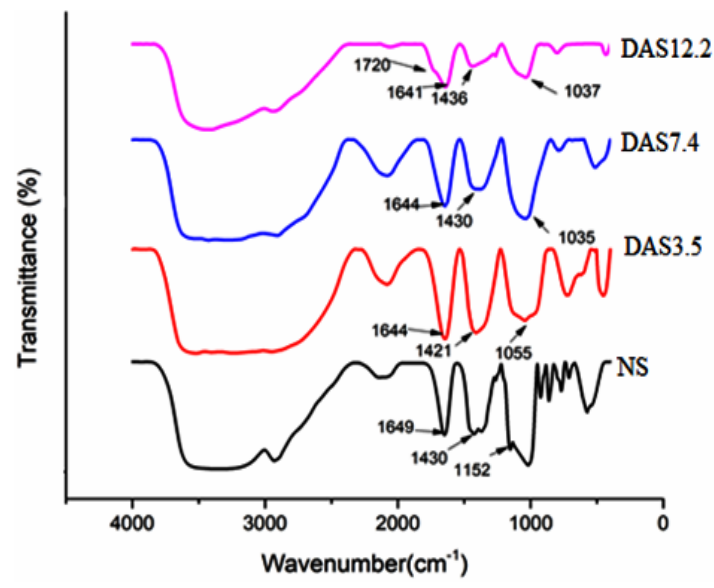

Fig. 1. FTIR spectra of native and dialdehyde starch

For NS, the main characteristic groups were the secondary -OH groups at the position of $\mathrm{C}_{2}$ and $\mathrm{C}_{3}$, the primary $-\mathrm{OH}$ groups at the position of $\mathrm{C}_{6}$, and the D-pyranose ring structure. These structural characteristics in the infrared spectrogram are shown as follow. The broad peak at $3310 \mathrm{~cm}^{-1}$ correlates to the $-\mathrm{OH}$ stretching. The peak absorption observed at $2930 \mathrm{~cm}^{-1}$ is atributed to $\mathrm{C}-\mathrm{H}$ stretching vibrations. The bound water in the starch was performed by the peak near $1640 \mathrm{~cm}^{-1} 4,6-8$. The peaks in range of $1000-1200 \mathrm{~cm}^{-1}$ are attributed to the $\mathrm{C}-\mathrm{O}$ bond of stretching and vibration ${ }^{4}$. The oxidation of starch by potassium periodate led to the linkage break at the position of $\mathrm{C}_{2}$ and $\mathrm{C}_{3}$ of the anhydroglucose units. The hydroxyl groups at $\mathrm{C}_{2}-\mathrm{C}_{3}$ was taken place by aldehyde groups. The peak of the $\mathrm{C}-\mathrm{O}$ bond stretching in $\mathrm{C}-\mathrm{O}-\mathrm{H}$ group in the anhydrogluscose ring of starch was observed near $1150 \mathrm{~cm}^{-1}$. With the rising in contents of aldehyde in starch, the double peak of $\mathrm{C}-\mathrm{OH}$ groups turned to a board band and gradually weakened. For DAS12.2 besides those peaks, there was an apperance of the peak around $1720 \mathrm{~cm}^{-1}$, represented the $\mathrm{C}=\mathrm{O}$ stretching and vibration ${ }^{4}$. This peak was not found in the spectra of DAS3.5 and DAS7.4 due to the low content of aldehyde groups in these samples. 


\section{XRD analysis}

The method of X-ray diffractometry was applied to analyse the crystal structure of natural and dialdehyde starch (Figure 2).

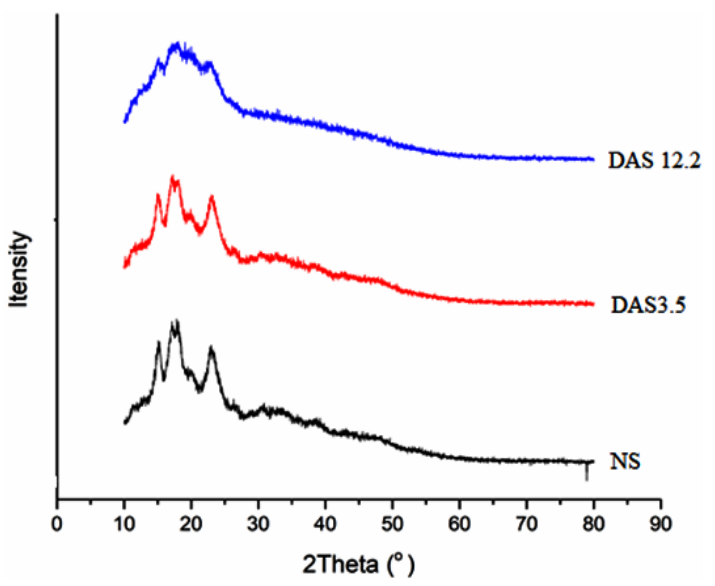

Fig. 2. XRD patterns of NS and the dialdehyde starch samples with $3.5 \%$ and $12.2 \%$ aldehyde contents

X-ray diffraction peak positions of NS were around $14.90,16.70,18.30$ and 22.60 of $2 \theta$, suggesting A-type crystals $\mathrm{s}^{4,9}$. These peaks gradually disappeared when increasing the oxidation degree, indicating that NS showed higher crystallinity comparing with DAS. This phenomenon might be related to the oxidation process of starch (Scheme 1$)^{4,6,9}$.

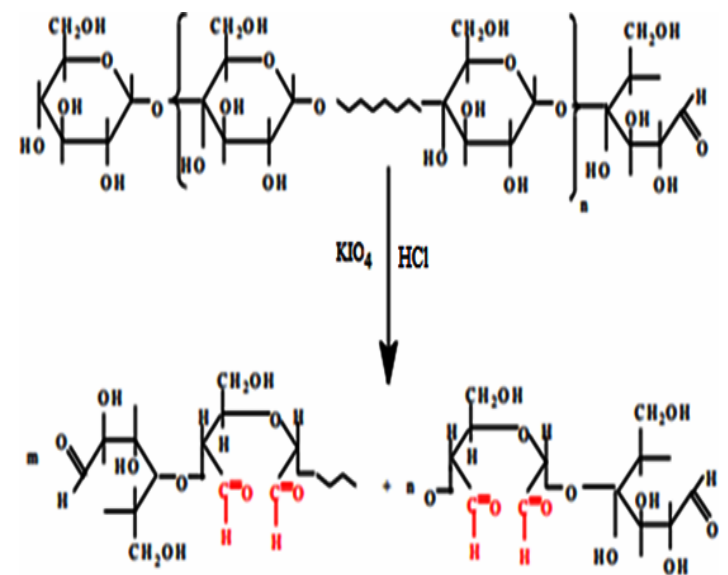

Scheme 1. The process of oxidation and acid hydrolysis of starch $^{4}$

The hydroxyl groups at the position of $\mathrm{C}_{2}$ and $\mathrm{C}_{3}$ of anhydroglucose units are oxidized with the formation of aldehyde groups, hence destroying the hydrogen bonds between starch molecules (Scheme $1)^{4}$. Moreover, the oxidation using periodate was conducted at $\mathrm{pH}$ of 3 , which might partially hydrolys the glycosidic bonds between glucose units in starch. These phenomena led to the cleavage in starch chain and formation of small crystallites exhibiting amorphous phase in DAS ${ }^{4,6,9,10}$.

\section{Thermogravimetric analysis (TGA) and differential thermogravimetry (DTG)}

TGA and DTG curves for NS and DAS12.2 are shown in Fig. 3. For DAS there were two stages of weight loss. The first stage around $30-120^{\circ} \mathrm{C}$ was related to the loss of water. The second one represented the decomposition of DAS with the maximum decomposition in the range of 249.6$270.8^{\circ} \mathrm{C}$. For the native starch there were three stages of weight loss. The first stage around $30-120^{\circ} \mathrm{C}$ was related to the loss of water. The double peaks were attributed to the stages of starch decomposition. It was shown that the maximum decomposition was at a range of $269.0-292.3^{\circ} \mathrm{C}$. With the existence of $-\mathrm{CHO}$ groups, the maximum peak shifted to region of lower temperature. It indicated the lower thermal stability of DAS in comparison with NS. This phenomenon might be related to the decline in evarage molecular weight of DAS 12.2 comparing to NS ${ }^{11}$.
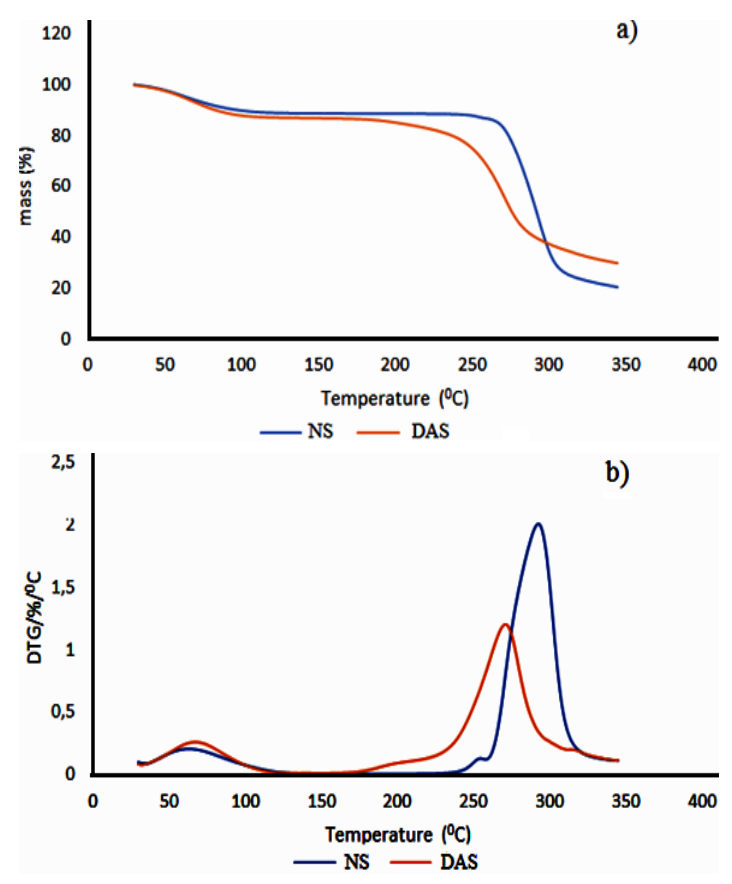

Fig. 3. The curves of TGA (a) and DTG (b) of NS and DAS12.2

\section{Hydrophilicity of Ge-DAS films}

The blend films containing DAS with higher aldehyde contents exhibited lower hydrophilicity, expressed in lower moisture content, solubility, and swelling capacity (Table 3 ). The first reason is the lower hydrophilicity of carbonyl groups in DAS 
compared to hydroxyl groups in native starch ${ }^{11}$. The second reason is the crosslinks between the aldehyde groups in DAS with amino groups in gelatin (to form imine) and with hydroxyl groups in unoxidized fragments in DAS (to form acetal and cetal) $^{12}$. These crosslinks tightened the film structure, hence lowering the the amount of moisture in the samples, hindering dissolution and suppressing the water diffusion into the film maxtric.

Table 3: The MC, S and WS of the Ge-DAS films

\begin{tabular}{lccc}
\hline Samples & $M C(\%)$ & $S(\%)$ & $S W(\%)$ \\
\hline Ge-NS & $31.38 \pm 1.57$ & $25.82 \pm 1.29$ & $134.80 \pm 6.50$ \\
Ge-DAS3.5 & $27.20 \pm 1.36$ & $19.77 \pm 0.10$ & $124.67 \pm 6.23$ \\
Ge-DAS7.4 & $22.26 \pm 1.13$ & $18.19 \pm 0.91$ & $122.24 \pm 6.11$ \\
Ge-DAS12.2 & $17.95 \pm 0.90$ & $15.68 \pm 0.78$ & $118.62 \pm 5.93$ \\
\hline
\end{tabular}

Mechanical properties of Ge-DAS films

Table 4 showed the values of the tensile strength (TS), elongation at break (EB) and Young's modulus (YM) of the blend films with different aldehyde contents.

Table 4: The value of TS, EB and YM of the films with different aldehyde contents

\begin{tabular}{lccc}
\hline Sample & TS $(\mathrm{MPa})$ & $\mathrm{EB}(\%)$ & $\mathrm{YM}(\mathrm{MPa})$ \\
\hline Ge-NS & $1.203 \pm 0.096$ & $23.628 \pm 4.934$ & $9.548 \pm 1.943$ \\
Ge-DAS3.5 & $1.452 \pm 0.254$ & $91.338 \pm 29.898$ & $3.058 \pm 0.661$ \\
Ge-DAS7.4 & $1.088 \pm 0.307$ & $54.471 \pm 6.711$ & $2.280 \pm 0.464$ \\
Ge-DAS12.2 & $0.679 \pm 0.080$ & $37.428 \pm 6.974$ & $2.019 \pm 0.313$ \\
\hline
\end{tabular}

The mechanical properties of the blend films were affected by the oxidation degree of starch. The low degree of starch oxidation (sample GeDAS3.5) caused a decline in the stiffness (YM) and a rise in the extensibility of the films (EB) comparing with the films of natural starch (Ge-NS). When the films containing DAS at the higher level of oxidation (Ge-DAS7.4 and Ge-DAS12.2), they exhibited lower stretchability, which was associated with decreases in EB of the films. The values of TS and YM also decreased when the degree of starch oxidation in the films increased. In a previous study, for the Ge-NS films, we showed that the change of tensile characteristics indicated the variation of degree of hydrogen bonding between $-\mathrm{NH}_{2}$ groups in gelatin and $-\mathrm{OH}$ groups in starch $^{13}$. However, for Ge-DAS films, the tensile properties are associated to the crosslinking reaction between $-\mathrm{CHO}$ and $-\mathrm{NH}_{2}$ groups in a polymeric matrix. The change in crosslinking reaction in Ge-DAS matrix might not corespond to the change of the level of starch oxidation. It was related to the heterogeneous property due to containing of both hydroxyl and carbonyl in the polymeric chain. This phenomenon might produce hindrances to the formation new crosslinking reaction in the polymeric matrix5. Another possible reason for the decreases in TS and YM at high degree of oxidation is the depolymerization of starch $^{14}$.

\section{CONCLUSION}

DAS was successfully prepared in a slightly acidic solution using $\mathrm{KIO}_{4}$ as the periodate oxidant. The oxidation introduced aldehyde groups into the starch backbone, destroyed the crystallinity of starch, and decreased the thermal stability of starch. DAS was blended with gelatin to produce biodegradable films with lower hydrophilicity due to the crosslinking aldehyde groups in DAS with functional groups of gelatin. The value of elongation at break and tensile strength of Ge-DAS films increased at low and decreased at high degrees of starch oxidation. Therefore, controlling the degree of periodate oxidation is a way of altering the physicochemical properties of film from DAS and other polymers.

\section{ACKNOWLEDGEMENT}

The authors are grateful to Science Research and Technology Transfer Institute, Industrial University of Ho Chi Minh City and Faculty of Chemical and Food Technology, Ho Chi Minh City University of Technology and Education for supports in facilities and equipment. We thank Dr. ChienThang Tran for careful reading of the manuscript and insightful comments.

\section{Conflict of interest}

The authors declare that there is no conflict of interest.

\section{REFERENCES}

1. Gironi, F.; Piemonte, V. Ener. Sour. Part a: Re., Utiliz., and Environ. Effects., 2011, 33(21), 1949-1959.

2. Gross, R. A.; Bhanu, K. Science., 2002 , 297(5582), 803-807.

3. Ghasemlou, M.; Aliheidari, N.; Fahmi, R.,
Shojaee-Aliabadi, S., Keshavarz, B., Cran M.J.; Khaksar R. Carbohyd. polymers., 2013, 98(1), 1117-1126.

4. Zuo, Y.; Liu, W.; Xiao, J.; Zhao, X.; Zhu, Y.; Wu, Y. Inter. J. of Biological macromolecules., 2017, 103, 1257-1264. 
5. Moreno, O.; Cárdenas, J., Atarés, L.; Chiralt, A. Carbohydrate Polymers., 2017, 178, 147-158.

6. Yu, J.; Chang, P. R.,; Ma, X. Carbohydrate Polymers., 2010, 79(2), 296-300.

7. Zuo, Y.; Gu, J.; Yang, L.; Qiao, Z.; Tan, H.; Zhang, Y. Inter. J. of Bio.macromolecules., 2013, 62, 241-247.

8. Ma, X.; Yu J.; Wang, N. Macro. Mat.and Eng., 2007, 292(6), 723-728.

9. Hoover, R.; Hughes, T.; Chung, H. J.; Liu, Q. Food Res. Inter., 2010, 43(2), 399-413.

10. Zhang, Y. R.; Wang, X. L.; Zhao, G. M; Wang,
Y. Z. Carbohydrate Polymers., 2012, 87(4) 2554-2562.

11. Zhang, L.;Liu, P.;Wang,Y.;Gao,W. Thermochimica Acta., 2011, 512(1-2), 196-201.

12. Mu, C.; Guo, J.; Li, X.; Lin, W.; Li, D. Food Hydrocolloids., 2012, 27(1), 22-29.

13. Nguyet, L. T. B, Nguyen, V. T. Orient J. Chem., 2020, 36(6), 1088-1095.

14. Fonseca, L. M.; Gonçalves, J. R.; El Halal, S. L. M.; Pinto, V. Z.; Dias, A. R. G.; Jacques,A. C; da Rosa Zavareze, E. LWT-Food Sci. and Tech., 2015, 60(2), 714-720. 